\title{
حت الحصول على المعلومات في المواثيق الدولية والتشريعات الوطنية مع إنشارة خاصة إلى اقليم كوردستان - العراق
}

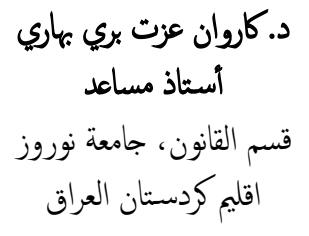

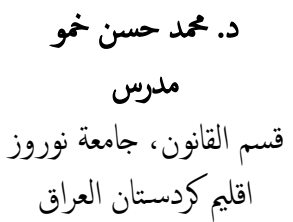

المستخلص

إنطلاقاً من فلسفة الترابط بين الحقوق وعدم قابليتها للتجزئة فإن الحق في تداول المعلومات يشكل أداة لتفعيل ممارسة حقوق أخرى بكافة صنوفها وأشكالها، فضلاً عن كونه يمثل

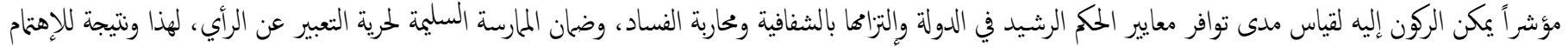

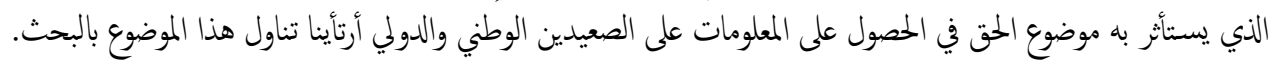
الكلمات الدالة : حق الحصول على المعلومات، الإعلان العالمي لحقوق الإنسان 1948، قانون حق الحصول على المعلومات في اقليم كودستان المرق (11) لسنة 2013، مبدأ الكشف الأقصى عن المعلومات.

التزكيز على إبراز التنظيم القانوني لحق الحصول على المعلومات في اقليم كوردستان.

1. المقدمة

تنبع أهمية موضوع البحث من كون حق الحصول على المعلومات يشكل آلية هامة 1.3 إثكالية البحث

تمتحور إشكالية موضوع البحث حول إيجاد آلية مناسبة لمعالجة حق الحصول على المعلومات، بجيث تتيح هذه الآلية إمكانية الإستفادة من هذا الحق من قبل المواطنين من ناحية، فضلاً عن تهيئة البيئة المناسبة كي يمارس هذا الحق دوره كوسيلة لمحاربة الفساد وتحتيق الحكم الرشيد من ناحية أخرى، وتتمحور تساؤولات البحث حول

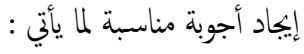

1. ما هو موقق الدساتير العربية والغربية من حق الحصول على المعلومات ؟ 2. ما هي الآليات التي إنتهجها المجتمع الدولي لتنظيم حق الحصول على المعلومات ؟ 3. ماهي القيود التي تحد من فاعلية مارسة حق الحصول على المعلومات على أرض

ههدف البحث إلى إبراز التنظيم القانوني الوطني والدولي لحت الحصول على المعلومات، الواقع ؟ 4. ما هو موقف المشرع العراقي والكوردستاني من هذا الحق ؟ 1.4 فرضية البحث

لابد لكل بحث من فرضية ينطلق منها الباحث ويحاول إثباتها وفرضيتنا في هذا البحث هي أن المعالجة الدولية والوطنية (الدساتير والقوانين الخاصة) المتعلقة بحق الحصول على تلى تل المعلومات،

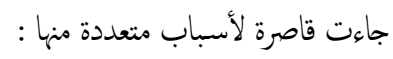
وعملية لدع وتعزيز فئة الحقوق الإقتصادية والإجتاعية والثقافية من جانب إضافة إلى إعتباره المكون الأساسي لمجموعة الحقوق المدنية والسياسية من جانب آخر، الأمر الذي يستوجب إتخاذ كافة الإجراءات التي تضمن وتحمي هذا الحت بالنسبة للمواطنين والذي يؤدي في حال تحققه وتنظمه تنظياً موضوعياً منسجاً مع المعايير الدولية، إلى تقيق تنمية إنسانية حقيقة وتوفير مناخ ديمقراطي حر في الدولة، فضلاً عما تقدم فإن الإثارة إلى قانون حق الحصول على المعلومات في اقليم كوردستان يشكل أهمية تستوجب الدراسة. 1.2 ومن ثم مطابتها مع المعايير التي أوردتها منظمة المادة (19) الخاصة بحرية التعبير عن الرأي وحق الحصول على المعلومات على إعتبارها منظمة متخصصة في هذا المجال، مع

المجلة الاكاديمية لجامعة نوروز, المجلد 8, العدد 1 (2019) ورقة بحث منتظمة نشرت في 2019/3/25 الركا

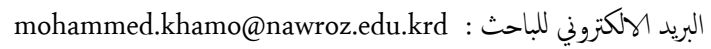
حقوق الطبع والنشر (C) 2017 أسهاء المؤلفين. هذه مقالة الوصول اليها مفتوح موزعة تحت رخصة

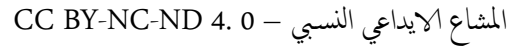


كفلت المواثيق الدولية حق الحصول على المعلومات سواءًان ذلك على الصعيد العالمي أم الأقليم، لذلك ومن أجل الإحاطة بتلك المواثيق فقد قسمنا هذا المبحث إلى مطلبين الأول خصصناه للمواثيق العالمية أما الثاني فقد تطرقنا فيه إلى المواثيق الأقليمية وكما يلي :

\section{1 حق الحصول على المعلومات في المواثيق الدولية}

عالمياً ثمة العديد من المواثيق التي أثارت إلى حق الحصول على المعلومات سنتناولها في هذا المطلب وكما يلي : - ميل

\subsection{1 الإعلان العالمي لحقوق الإنسان (1)}

تعتبر المادة (19) من الإعلان العالمي لحقوق الإنسان الأساس القانوني الأول لحرية تداول المعلومات حيث تضمنت المماية المكفولة لحرية الرأي والتعبير المنصوص علهيا في المادة (19) حرية تداول المعلومات بنصها على ( لكل شخص حق التمتع بحرية الرأي والتعبير ، ويشمل هذا الحق حريته في إعتناق الآرآ دون مضايقة وفي إلتاس الأنباء ونقلها إلى الآخرين بأية وسيلة ودونما إعتبار للحدود). وثمة ملاحظات على النص أعلاه، يكن إجالها بما يلي : 1. النص لم يتطرق إلى حق الحصول على المعلومات بشكل مباثر، وإنما جاء هذا الحت ضمن نس المادة التي تحدثت عن حرية الرأي والتعبير، ولعل السبب في ذلك يعود إلى المعنى الواسع التي تتصف بها هذه الحرية والدليل على ذلك هي كلمة الشمول التي جاءت في الشق الثاني من نص المادة (19) (ويشمل هذا الحق. . . . . ) أي أن حق الحصول على المعلومات هو جزء من حرية الرأي والتعبير. 2. حدت المادة (19) من الإعلان العالمي لحقوق الإنسان مجالات رئيسية لحق الحصول على المعلومات الأول يتمثل بالحق في إلتاس المعلومات سواءاً أخذت هذه المعلومات صيغة الأنباء أم صيغة الأفكار، أما النطاق الثاني فهو الحق في تلقي المعلومات أي إستلاما من الغير سواءً كان هذا الغير (حكومة أم أفراد) أما النطاق الثالث فيتمثل بالحق في نشر المعلومات وإذاعتها. 3. كما يلاحظ على المادة (19) من الإعلان العالمي لحقوق الإنسان أنها لم تقيد ممارسة حق الحصول على المعلومات بأية قيود.

2.1.2 العهد الدولي الخاص بالحقوق المدنية والسياسية (2) أقرت المادة (19) من العهد الدولي الخاص بالحقوق المدنية والسياسية حت الحصول على المعلومات، حيث جاء فيها ( 1- لكل إنسان الحق في إعنتاق الآرآ دون مضايقة
1. كثرة القيود التي تفرضها هذه الدساتير والقوانين الخاصة على حق الحصول على المعلومات، الأمر الذي يفقد هذا الحتق قيمته في الواقع العملي. 2. عدم مراعاة مبادىء منظمة المادة (19) الخاصة بحق الحصول على المعلومات من

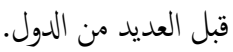

أعتمدنا في كتابة البحث على المنهج التحليلي الذي يعول على تحليل نصوص المواثيق الدولية والدساتير الوطنية والقوانين الخاصة التي تناولت هذا الموضوع بالتنظيم مع الإنشارة بصفة خاصة إلى موقف قانون اقليم كوردستان العراق رق (11) لسنة 2013.

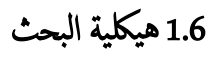

لغرض الإحاطة بموضوع البحث من جوانبه كافة أرتأينا تقسيمه إلى ثلاثة مباحث، خصصنا المبحث الأول لدراسة حق الحصول على المعلومات في الدساتير والقوانين الوطنية من خلال مطلبين، تطرقنا في المطلب الأول إلى حق الحصول على المعلومات في الدساتير الوطنية، أما المطلب الثاني فقد خصصناه للبحث في حق الحصول على المعلومات في القوانين الوطنية، أما المبحث الثاني فتناولنا فيه حق الحصول على المعلومات في المواثيق الدولية وذلك في مطلبين الأول تناول تنظيم هذا الحق فب المواثيق العالمية، أما الثاني فقد تم تخصيصه للبحث في المواثيق الأقلمية، وتم تخصيص المبحث الثالث لدراسة قانون حق الحصول على المعلومات في اقليم كوردستان المرقز 2013 . 2011 (11)

\section{7 كلمات مفتاحية}

1. حق الحصول على المعلومات (The right to access to information) 2. الإعلان العالمي لحقوق الإنسان 1948 ( The universal declaration of (human rights 3. قانون حق الحصول على المعلومات في اقليم كوردستان المرق (11) لسنة 2013 Access to information code - Kurdistan region - No. $11-$ ) 4. منظمة المادة (19) (Article 19 organization). 5. مبدأ الكشف الأقصى عن المعلومات ( The principle of maximum .(disclosure of information 2. مت الحصول على المعلومات في المواثيق الدولية 
2. إلتماس وتلقي المعلومات الجديرة بالتصديق والثقة من الحكومات والمنظمات غير

الحكومية ومن أي أطراف أخرى على علم بهذه الحالات والرد على هذه المعلومات. 3. إعداد توصيات وتقديم مقترحات عن السبل والوسائل الكفيلة بتحسين وتعزيز وحاية الحرق في حرية الرأي والتعبير بكل مظاهره. 4. الإسهام فيما تضطلع به مفوضية الأم المتحدة السامية لحقوق الإنسان من تقديم للمساعدة الثتية والخدمات الإستشارية لتحسين وتعزيز وحاية الحت في حرية الرأي والتعبير. وقدر تعلق الأمر بدور المقرر الخاص من حق الحصول على المعلومات فقد أصدر تقريره السنوي عام 1998، وصرح من خلاله بوضوح من أن الحق في حرية التعبير يتضمن الحق في الحصول على المعلومات التي تتنفظ بها الدولة عنا قال ( إن حق البحث والتسليم ونقل المعلومات يفترض إلتزاماً إيجابياً على الدول لضمان الوصول إلى المعلومات بخاصة فيم يتعلق بالمعلومات التي تختفظ بها الحكومة بكافة أشكال أنظمة الحفظ والإسترجاع) (8)، وتوسع المقرر بشكل كير في رؤيته لحرية المعلومات في تقريره السنوي لسنة 2005، حيث أثار إلى أهميتها ليس بالنسبة للديمقراطية والحرية

$$
\text { فسب بل للحق في المشاركة وتحتيق التنمية أيضاً (9). }
$$

2.1.5 إتفاقية الأم المتحدة ململفة الفساد (10)

تعد إتفاقية الأم المتحدة ملهافة الفساد من الإتفاقيات التي أشارت إلى حق الحصول على المعلومات، وإن كان ذلك بشكل أضيق مما أشارت إليه المواثيق آنة الذكر، حيث تطرقت الإتفاقية إلى هذا الحق كوسية للحد من ظاهرة الفساد، وهذا ما يككن إستنتاجه من نصا على ( 1- تتخذ كل دولة طرف تدابير مناسبة ضمن حدود إمكانياتها ووفقاً للمبادىء الأساسية لقانونها الداخلي لتنجيع الأفراد والجماعات التي لا تنتي للقطاع العام مثل المجتمع الأهلي والمنظات غير الحكومية ومنظات المجتمع المحلي، على المشاركة النشطة في منع الفساد ومحاربته ولإذكاء وعي الناس فيا يتعلق بوجود الفساد وأسبابه وجسامته وما يمثله من خطر وينبني تدعيم هذه المشاركة بتدابير مثل

$$
\begin{aligned}
& \text { : أ. تعزيز الشفافية في عمليات إتخاذ القرار وتشجيع إسهام الناس فها. } \\
& \text { ب. ضان تيسير حصول الناس فعلياً على المعلومات. }
\end{aligned}
$$

ج. القيام بأنشطة إعلامية تسهم في عدم التسامح مع الفساد وكذلك برامج توعية عامة تشمل المناجج الدراسية والجامعية.
2- لكل إنسان الحق في حرية الرأي والتعبير ويشمل هذا الحق حريته في إلتاس مختلف ضروب المعلومات والأفكار وتلقيها ونقلها إلى الآخرين، دونما إعتبار للحدود سواءً على شكل مكتوب أو مطبوع أو في قالب فني بأي وسيلة أخرى يختارها...)(3).

\subsection{3 العهد الدولي الخاص بالحقوق الإقتصادية والإجتاعية والثقافية (4)}

أشارت المادة (15) من العهد الدولي الخاص بالحقوق الإقتصادية والإجتاعية والثقافية إلى حق الحصول على المعلومات وإن كان ذلك بشكل ضمني حيث نصت على ما يلي 1. تقر الدول الأطراف في هذا العهد بأن من حق كل فرد في : أ. أن يشارك في الحياة الثقافية. ب. أن يتمتع بفوائد التقدم العلمي. ت. أن يفيد من حاية المصاح المعنوية والمادية الناجمة عن أي أثر علمي أو فني أو

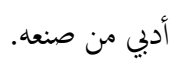

2. تراعي الدول الأطراف في هذا العهد في الندابير التي ستتخذها بغية ضان المارسة الكاملة لهذا الحق، أن تشمل تلك التدابير التي تتطلهيا صيانة العلم والثقافة وإغنائها وإنشاعها.

3. تتعهد الدول الأطراف في هذا العهد بإحترام الحرية التي لا غنى عنها للبحث العلمي والنشاط الإبداعي. 4- تقر الدول الأطراف في هذا العهد بالفوائد التي تجنى من تشجيع وإنماء الإتصال والتعاون الدوليين في ميداني العلم والثقافة) (5.) والملاحظ على هذا العهد أنه قد أشار إلى حق الحصول على المعلومات ولكن بصيغة ختبلفة عما ورد في كل من الإعلان العالمي لحقوق الإنسان والعهد الخاص بالحقوق المدنية والسياسية، حيث جاءت الصيغة هنا محددة أكثر وهذا ما يمكن أستنتاجه من تأكيد المادة (15) على حق كل فرد في المشاركة في الحياة الثقافية والتتع بفوائد التقدم العلمي والتكنولوجي وهو ما يدخل في نطاق طلب المعرفة وإلتاس المعلومات، ومن البدهي أن هذا المجال لا يككن الولوج فيه دون أن يكون الحق في المعرفة وتداول المعلومات مكفولاً من جانب الدول الأطراف في العهد.

\subsection{4 المقرر الخاص المعني بتعزيز وحاية الحق في حرية الرأي والتعبير(6)}

تتمثل محام المقرر الخاص المعني بتعزيز وحاية الحق في حرية الرأي والتعبير بما يلي : (7) 1. مجع كل ما يتوافر من معلومات مناسبة تتصل بإنتهات الحق في حرية الرأي 


\section{المبدأ الخامس : عمليات تسهيل الحصول على المعلومات}

والمقصود به معالجة طلبات الحصول على المعلومات بشكل سيع وعادل، وتوفير المراجعة المستقلة لأي رفض بالكشف عن المعلومات، وأن ينص القانون على إجراءات واضحة حول كيفة تقديم الطلبات وكيفية اتخاذ القرارات من قبل الهيئات

العامة.

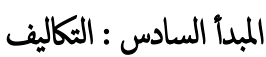

لا ينبني إعاقة الأفراد عن تقديم طلبات الحصول على المعلومات من خلال فرض رسوم كبيرة.

المبدأ السابع : الاجتزاعات المفتوحة ينبني أن تكون اجتاعات الهيئات العامة مفتوحة للجمهور. المبدأ الثامن : الإفصاح هو السائد ضرورة تعديل أو إلغاء القوانين التي لا تتوافق مع مبدأ الإفصاح الكامل.

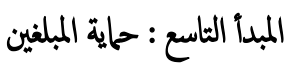
يجب حاية الأشخاص الذين يكشفون عن المعلومات المتعلقة بأي ممارسات خاطئة (المبلغين) ضد أي عقوبات قانونية أو إدارية أو وظيفية (13).

\section{2 حتى الحصول على المعلومات في المواثيق الأقلمية}

إلى جانب المواثيق العالمية التي أشارت إلى حق الحصول على الملعومات، ثمة مواثيق أقليمية لم تغفل هي الأخرى هذا الحق ومن أجل بيان مضمون حق الحصول على المعلومات في تلك المواثيق سنتناولها في هذا المطلب وكما يلي : 2.2.1 الإثفاقية الأوروبية لحقوق الإنسان وحرياته الأساسية (14) أشارت الإتفاقية الأوربية لحقوق الإنسان إلى الحق في الحصول على المعلومات بنصها على (1- لكل شخص الحق في حرية التعبير ، ويشمل هذا الحق حرية تلتي المعلومات أو الأفكار وإذاعتها من دون تدخل السلطات العامة ومن دون التقيد بالحدود الجغرافية. . . . ) (15). مما تقدم يتضح لنا أن الإتفاقية الأوربية قد نصت وبشكل صريح على حق الحصول على المعلومات، والأفكار وإذاعها دون الإعترف أو التقيد بالحدود الجغرافية، إلا أن الإنفاقية ذاتها نصت على إمكانية إخضاع ممارسة هذا الحق لبعض القيود والشروط إذا كان الغرض منها الحفاظ على سلامة الوطن وأراضيه أو حاية

$$
\text { النظام العام وحقوق الآخرين وسمعته. }
$$

د. إحترام وتعزيز وحاية حرية إلتاس المعلومات المتعلقة بالفساد وتلقيها ونشرها ونعميهها، وييوز إخضاع تلك الحرية لقيود معينة، شريطة أن تقتصر هذه القيود على ما ينص عليه القانون وما هو ضروري لما يلي : 1. لمراعاة حقوق الآخرين وسمعته. 2. لماية الأمن الوطني أو النظام العام أو لصون صحة الناس أو أخلاقهم)(11).

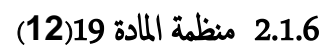

بالرجوع إلى المادة 19 من الأعلان العالمي لحقوق الانسان نجد أنه قد أعترف بأن حرية الوصول إلى المعلومات حق أساسي من حقوق الانسان، وأن هناك حاجة لقوانين فاعلة لضانها، ومن أجل أن يصبح هذه الأمر مككناً أصدرت منظمة المادة 19 المبادئ التسعة العالمية، وتثثل هذه المبادئ الحد الأدنى الواجب توافره في قوانين حرية تداول المعلومات في أي دولة تخطو نخو الديمقراطية والحكى الرشيد، وهذه المبادئ هي : المبدأ الأول الإفصاح الكامل والمتضمن ضرورة أن يكون الإفصاح عن المعلومات هو القاعدة والعرف المتبع، كما ينبني أن يكون بإمكان أي شخص طلب المعلومات وليس فقط مواطني البلد، ولا ينبغي أن يُشترط على الشخص أن يقدم أي مبررات أو أن يكون لديه مصلحة معينة عند

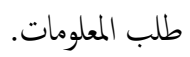

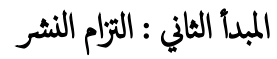
يقصد بهذا المبدأ ضرورة أن تُلتزم الهيئات العامة قانونياً بأن تنثر المعلومات الموجودة بحوزتها، وينبني أن تنشر الهيئات العامة بشكل استباقي المعلومات وكذلك أن

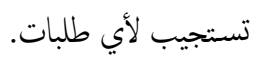

\section{المبدأ الثالث : التشجيع على المكومة المنفتحة}

ومعناه ينبني أن تروج الهيئات العامة بشكل نشط للحكومة المنفتحة، ويعتمد ذلك الانقتاح على تحدي المارسات والسلوكيات التي تحمي ثقافة السرية المتجذرة، وتدريب الموظفين العموميين. المبدأ الرابع : محدودية نطاق الاستثناءات يجب أن تكون أي استثناءات على الحق في الوصول إلى المعلومات واضحة وضيقة وأن تخضع لاختبارات “الضرر” و “المصلحة العامة” 
الفاعل إذا أتى أمراً وهو بصدد ممارسة الحق من شأنه الإضرار بسمة الآخرين أو النظام العام بمختلف عناصره أو الأمن القومي.

2.2.5 الميثاق العربي لحقوق الإنسان (23)

على غرار المواثيق الأقليمة التي أشرنا إلها سابقاً، جاء الميثاق العربي لحقوق الإنسان متضمناً النص على حق تداول المعلومات وهذا ما يمكن إستنتاجه من نص المادة (33) التي تنص على (1- يضمن هذا الميثاق الحق في الإعلام وحرية الرأي والتعبير وكذلك الحق في إستقاء الأنباء والأفكار وتلقيها ونقلها إلى الآخرين بأي وسيلة ودونما إعتبار للحدود الجغرافية. 2- تمارس هذه الحقوق والحريات في إطار المقومات الأساسية للمجتع ولا تخضع إلا للقيود التي يفرضها إحترام حقوق الآخرين أو سمعته أو حاية الأمن الوطني أو النظام العام أو الصحة العامة أو الآداب العامة). 2.3 حق الحصول على المعلومات في الدساتير والتشريعات الوطنية (24) تعرف المعلومات بأهها (كل ما يعرفه الإنسان عن قضية أو حادثة) وتعرف بأنها أيضاً ( الحقائق عن أي موضوع أو الأفكار والحقائق عن الناس والأماكن أو أي معرفة تكتسب من خلال الإتصال أو البحث أ, التعلم أو الملاحظة) (25.) ويراد بحق الحصول على المعلومات ( تمكين الأشخاص من مصادر الأخبار والمعلومات والإحصاءات والأستفسار عنها والإطلاع على كافة الوثائق الرسمية غير المخظورة، وذلك دون عائق يحول بينه وبين حرية تدقيق المعلومات أو يحول دون نكافوء الفرص ببنه وبين غيره)(26). تناولت بعض الدساتير الغربية منها والعربية حق الحصول على المعلومات بالتنظيم، فضلاً عن إصدار بعض الدول لقوانين لمعالجة هذا الموضوع أو الحق لذلك ومن أجل الإحاطة بالمعالجة التشريعية لحق الحصول على المعلومات، قسمنا هذا المبحث إلى مطلبين ، يتناول الأول موقف الدساتير من حق الحصول على المعلومات، ببنا يعاج المطلب الثاني التشريعات الوطنية وكيفية تنظيمها لهذا الحق.

\section{4 حتى الحصول على المعلومات في الدساتير الوطنية}

تطرقت العديد من الدساتير الغربية والعربية إلى حق الحصول على المعلومات وتداولها، سنشير في هذا المطلب إلى موقف تلك الدساتير وآليات معالجة هذا الحق. فعلى صعيد الدساتير الغربية، نص الدستور الإسباني على حق الحصول على المعلومات وتداولها بقوله يتم الإعتراف بالحقوق التالية والإقرار بحايتها : ( الحق في تبيلغ المعلومات الصحيحة وتلقهيا بحرية من خلال أية وسيلة نثر وينظم بقانون)(27). وهذا يعني أن الدستور الإسباني قد أقر المواطنين بجق تلقي المعلومات وتداولها بأية وسيلة من

\subsection{2 ميثاق الحقوق الأساسية الأوريي (16)}

كفل ميثاق الحقوق الأساسية الصادر عن الإتحاد الأوربي للمواطن حرية الرأي فضلاً عن حق الحصول على المعلومات، حيث نص على (1- لكل شخص الحق في حرية التعبير، ويشمل هذا الحت حرية إعتناق الآرآ وتلتي ونقل المعلومات والأفكار دون تدخل من السلطة العامة وبصرف النظر عن الحدود. 2- تحتزم حرية وتعددية وسائل الإعلام) (17.) وهذا يعني أن هذا الميثاق قد كفل حرية وحق الحصول على المعلومات دون تدخل من قبل السلطات العامة ودون مراعاة لأي حواجز. 2.2.3 الميثاق الأفريقي لحماية حقوق الإنسان والشعوب (18) كفل الميثاق الأفريقي لماية حقوق الإنسان والشعوب حرية تداول المعلومات والحصول عليها حيث نص الميثاق على (1- من حق كل فرد أن يحصل على المعلومات. 2يحق لكل إنسان أن يعبر عن أفكاره ونشرها في إطار القوانين واللوائح) (19). وتجدر الإشارة هنا إلى أن اللجنة الأفريقية لحقوق الإنسان والشعوب قد تبنت إعلان مبادى حرية التعبير في دورة إنعقادها الثانية والثلاثين عام 2002 وقد أيد هذا الإعلان بوضوح الحق في إناحة المعلومات مقرراً الآتي : (20) 1. إن الجهات العامة لا تتفظ بالمعلومات لنفسها بل كنائب عن الصاح العام، وكل فرد يتتع بالحق في إتاحة المعلومات. 2. أن القانون سيضمن للجميع الحصول على المعلومات. 3. يتنع الجميع بحق الحصول على معلوماتهم الشخصية وتحديثا وبطريقة ما تصحيحها سواءً كانت تتنفظ بها بهات عامة أم خاصة. 2.2.4 الإثفاقية الأمريكية لحقوق الإنسان (21)

تناولت الإثفاقية الأمريكية لحقوق الإنسان بالتنظيم حق الحصول على المعلومات بالنص على ( 1- لكل إنسان الحت في حرية الفكر والتعبير ويشمل هذا الحت حريته في البحث عن مختلف أنواع المعلومات والأفكار وتلقيها ونقلها إلى الآخرين، دونما إعتبار للحدود، سواؤ شفاهاً أو كنابةً أو طباعةً أو في قالب فني أو بأي وسيلة يختارها. 2لا يجوز أن تخضع ممارسة الحق المنصوص عليه في الفقرة السابقة لرقابة مسبقة بل يمكن أن تكون موضوعاً لفرض مسؤولية لاحقة يحددها القانون صراحة وتكون ضرورية من أجل : أ- إحترام حقوق الآخرين وسمعته. ب- حاية الأمن القوي أو النظام العام أو الصحة العامة أو الأخلاق العامة) (22.) والملاحظ على المادة أعلاه أنها منعت إخضاع مارسة الحقوق المذكورة فهيا لرقابة سابقة، إلا أهها أجازت تحريك مسؤولية لاحقة بحق 
على المواطنين، حيث أستثنى المقيمين الأجانب، وهذا بحد ذاته يتعارض مع المعايير الدولية ومعايير منظمة المادة (19) المتخصصة في مجال حرية التعبير عن الرأي وحق الحصول على المعلومات. إلى جانب الدستور المصري الذي كفل للمواطنين حق الحصول على المعلومات وتداولها، ضمن الدستور المغربي هو الآخر هذا الحق للمواطنين حيث نص على ( للمواطنات والموطنين حق الحصول على المعلومات الموجودة في حوزة الإدارة العمومية والمؤسسات المنتخبة والهيئات المكلفة بهام المرفق العام. لا يككن تقييد الحق في المعلومة إلا بمتضى القانون بهدف حاية كل ما يتعلق بالدفاع الوطني وحاية أمن الدولة الداخلي والخارجي والحياة الخاصة للأفراد وكذلك الوقاية من المس بالحريات والحقوق الأساسية المنصوص عليها في هذا الدستور وحاية مصادر المعلومات والمجالات التي يحددها القانون بدقة) (33). والملاحظ على الدستور المغربي أنه أتصف بخاصية كمة وهي أنه قد أجاز للمواطنين الحصول على المعلومات ليس من الجهات الحكومة العامة فسب وإنما من المؤسسات الخاصة أيضاً إذا كانت هذه المؤسسات مكلفة بتقديم خدمة عامة، إلا أن ما يؤخذ على الدستور المغربي والدساتير التي عالجت ونظمت حق الحصول على المعلومات هي كثرة القيود التي أوردتها على حق الحصول على المعلومات وتداولها بجيث تفقد هذه القيود من قيمة هذا الحق، حيث نجد أن هذه الدساتير تنص على حق المواطنين في الحصول على المعلومات بشرط عدم مخالفة القنون والنظام العام والحقوق الشخصية للمواطنين. ... • الخ وهذه القيود حسب وبجة نظرنا لا تبقي لهذا الحق قيمة فعلية على أرض الواقح، وفي هذا الصدد نقف موقف المنتقد من الدستور العراقي لعام 2005 الذي لم يتضمن نص يعاج هذا الحق وهذا بحد ذاته يشكل عيب كان من المفتض على المشرع الدستوري العراقي العمل على تلافيه أو تجنب الوقوع فيه.

\section{5 حت الحصول على المعلومات في التشريعات الوطنية}

عملت العديد من الدول الغربية منها والعربية على وضع حق الحصول على المعلومات وتداولها في متناول المواطنين وذلك من خلال إصدار قوانين في هذا الصدد، فالسويد تعتبر الدولة الرائدة في هذا المجال، حيث تعتبر السويد أول دولة على مستوى العالم تصدر قانوناً خاصاً ييزيز للمواطنين الحصول على المعلومات وتداولها حيث جاء في هذا القانون ما نصه ( يحق لكل مواطن سويدي الحصول على الوثائق الرسمية) (34)، كما بين القانون السويدي المقصود بالوثائق الرسمية بقوله ( الوثائق المحفوظة لدى سلطة حكومية وحتى يتم إعتبارها بموجب المادتين (6-7) من القانون فهي التي تم إستلاهما
وسائل النشر على أن تنظم عملية التلقي والتداول للمعلومات بموجب القانون، وحسناً فعل المشرع الدستوري الإسباني عندما قضى بعدم جواز تقييد ممارسة هذا الحق بأي نوع من أنواع الرقابة المسبقة (28.) ومن الدساتير الغربية الأخرى التي نصت على حق المواطنين في الحصول على المعلومات وتداولها الدستور الألماني لعام 1949 حيث كفل هذا الدستور للمواطن حق الحصول على المعلومات دون أي عائق عندما نص على (1- يحق لكل إنسان التعبير عن رأيه ونشره بالقول والكتابة والصورة، كما أن له الحق في الحصول على المعلومات بدون عائق من المصادر العامة، وتكفل حرية التغطية الإعلامية عبر الوسائل المسموعة والمرئية ولا يجوز فرض رقابة على ذلك. 2- تخضع تقييدات هذه الحقوق لأحكام القوانين العامة وأحكام القوانين الخاصة بحاية الأحداث والتشريعات الخاصة بحاية الشرف الشخصي)(29). كما ضمن الدستور السويسري المواطنين حق الحصول على المعلومات وتدولها بكافة الوسائل عندما نص على 1.يكفل الدستور حرية الرأي والمعلومات. 2. لكل شخص الحق في تكوين رأيه والتعبير عنه ونشره بكل حرية. 3. لكل شخص الحق في تلقي المعلومات والحصول عليها من مصادر المعلومات العامة ونشرها بكل حرية)(30). وضمن السياق نفه حرص الدستور الفنلندي على وضع الحق في تداول المعلومات ونتلها في متناول المواطنين عندما نص على (حرية التعبير مكفولة لكل شخص وتتضمن حرية التعبير والحق في إستقبال ونشر المعلومات والتعبير عن الآرآ والأتصالات الأخرى. 2- الوثائق التي تكون في حوزة السلطات تكون مباحة إلا إذا كان نشرها قد تم تقييده لأسباب ضرورية خاصة في القانون)(31)، والملاحظ على النص أعلاه أنه قد كفل للمواطنين الحق في الحصول على المعلومات وتداولها إلا أنه في الفقرة الثانية أجاز تقييد هذا الحق إذا كانت هناك ضرورة قانونية تستوجب ذلك. هذا على صعيد الدساتير الغربية أما على الصعيد العربي فالملاحظ أن السواد الأعظم من الدساتير العربية لم تشر إلى حق الحصول على المعلومات وتداولها يستثنى من ذلك بعض الدساتير ومنها الدستور المصري الذي نص على إعتبار المعلومات والبيانات الموجودة لدى الجهات ملك للشعب وهذا ما يككن أستنتاجه من نصه على (المعلومات والبيانات والإحصاءات والوثائق الرسمية ملك للشعب والإفصاح عنها من مصادرها المختلفة حق تكفله الدولة لكل المواطنين، وتلتزم الدولة بتوفيرها وإتاحتها للمواطنين بشفافية)(32). ويلاحظ على الدستور المصري أنه ضيق وبشكل كير من دائرة الأشخاص الذين يجق لم طلب المعلومات عندما جعل هذا الحق قاصراً 
المواطنين الأساسية ولمواطنين ممارسة هذا الحق في حدود القانون)، كما أكد هذا القانون على ضرورة تأمين وتسهيل حق المواطنين في الحصول على المعلومات فضلاً عن تأكيده على توسيع قواعد ممارسة الحقوق والحريات (40). والملاحظ على المشرع اليمني أنه قد جعل حق طلب المعلومات محصوراً بالمواطنين فقط وهو ما يعتبر نقطة سلبية تسجل على هذا القانون لأنه جاء على عكس ما تتطلبه المعايير الدولية والتي تقضي بجعل هذا الحق في متناول المجيع (مواطنين كنوا أم مقيمين على أرض الدولة). وفي فلسطين تم إصدار قانون خاص بحق الحصول على المعلومات سنة (2015) وقد جسدت المادة (2) من هذا القانون الهدف منه في فقرتين هما 1. تمكين المواطن والمقيم في فلسطين من ممارسة حق الحصول على المعلومات الموجودة لدى المؤسسات العامة وفقاً لأحكام هذا القانون. 2. بث روح روح الشفافية والمساءلة في المؤسسات العامة الفلسطينية وتشجيع الأنفتاح على الشعب. والملاحظ على قانون حق الخصول على المعلومات الفلسطيني أن لم يجعل حق الحصول على المعلومات حكراً على المواطن الفلسطيني حفسب وإنما شمل المقيم أيضاً بهذا الحق، وهي نقطة تحسب للمشرع الفلسطيني في هذا الصدد، وهذا الأمر يشكل تحولاً إيهابياً في موقف القوانين العربية، ومن المميزات التي أتصف بها القانون الفلسطيني، أنه أوجب على المؤسسات العامة نشر تقارير سنوية تتضمن معلومات حول آلية عمل المؤسسة والنكليف والإجراءات التي يستطيع الأفراد على أساسها التعرف على السياسات العامة لهذه المؤسسات، فضلاً عن أنواع المعلومات التي تحتفظ بها المؤسسات وحالات الإحتفاظ بها (41). وفي السودان تم إصدار قانون خاص بجق الخصول على المعلومات عام 2015، حيث كفل هذا القانون للمواطنين حق الحصول على المعلومات وتداولها وهذا ما يككن أستنتاجه من نص المادة (1) من الفصل الخامس التي جاء فها (يكون لأي شخص الحق في الإطلاع والحصول على المعلومات من مصادرها الأساسية من الأجزة والوحدات الحكومية على كافة مستويات الحكى ومؤسسات القطاع العام والشركات المساهمة العامة والشركات التي تشارك فيها المكومة بأي نسبة وأي مؤسسة عامة يرى الوزير المختص أنها تعمل عملاً مشابهاً للقطاع العام ومنظات المجتع المدني). والملاحظ على المشرع السوداني أنه لم يجعل إمكانية الحصول على المعلومات حكراً على المواطن السوداني وإنما جعل هذا الحق في متناول أي شخص أياً كانت صفة إرتباطه بالدولة سواءً كان مواطناً أم مقياً، كما أنه أعطى المؤسسسة العامة التي تقدم المعلومات صلاحيات فرض رسوم مالية
أو إعدادها أو كتابها من قبل سلطة معينة) (35). وفي الولايات المتحدة الأمريكية تم إقرار قانون خاص بحرية تداول المعلومات عام 1966 حيث يسمح هذا القانون لأي شخص بغض النظر عن موطنه أو الدولة الأصل التي ينتي إلها بالسؤال عن المعلومات التي تحتفظ بها هيئات الحكومة الفدرالية، وقضى هذا القانون على أنه (عند التأخر في توفير المعلومات المطلوبة فإن يجوز لطالها تقديم شكوى مباشرة إلى الهيئة المطلوب منها توفير المعلومات، ومن حق المحاك أن تراجع أي قرار خاص بحجب المعلومات وأن تقوم بإلغائه دون إعتبار للجهة التي أصدرته) (36). وعلى الصعيد العربي يبدو أن العديد من الدول العربية قد عملت على تلافي النقص الموجود في دساتيرها والمتمثل بعدم الإثارة إلى حق المواطن في الحصول على المعلومات وتداولها، لذلك حرصت تلك الدول على إصدار قوانين تعالج هذا الحق وتجعله في متناول المواطنين وتعتبر الأردن في مقدمة الدول العربية التي أصدرت قانوناً خاصاً بحق الحصول على المعلومات وتداولها، حيث جاء في هذا القانون مايلي (مع مراعاة التشريعات النافذة لكل أردني الحت في الحصول على المعلومات التي يطلبها وفقاً لأحكام هذا القانون إذا كانت له صلة مشروعة أو سبب مشروع)(37). والملاحظ على القانون الأردني الخاص بحق تداول المعلومات أنه قد جعل من حق طلب المعلومات وتداولها حصراً على المواطن الأردني وهذا يعني أن غير الأردني المقيم في الأردن لا يجق له طلب المعلومات من الهيئات الحكومية ولا الإطلاع عليها أو تداولها، هذا بحد ذاته يتعارض مع المعايير الدولية الخاصة بحق الحصول على المعلومات والتي تجعل هذا الحق في متناول الجميع بغض النظر عن كونه مواطناً أمر لا، كما يؤخذ على قانون الحصول على المعلومات الأردني أنه جعل مسألة تصنيف المعلومات ودرجة اهميتها إما للتشريع أو للجهة التي تتنفظ بالمعلومات، الأمر الذي يسمح للجهات أعلاه بتصنيف أية معلومات على انها من المعلومات المحمية - السرية - والتي يكنن للمسؤول الإمتناع عن إعطاهيا (38)، ومن الإنتقادات التي يكن تسجيلها على قانون حق الحصول على المعلومات الأردني أيضاً، أنه لم يحدد كلفة الحصول على المعلومات وإنما جعل ذلك من صلاحيات الجهة التي تقوم بتقديم المعلومات (39)، حيث كان من الأجدر بالمشرع الأردني تحديد كلفة الحصول على المعلومات ضمن نصوص التشريع الخاص بتنظيم حق الحصول على المعلومات، حتى لا يكون هناك مغالاة في تلك الكلفة، الأمر الذي قد يحول دون طلها. ومن الدول التي تمتلك قانون خاص بجق الحصول على المعلومات اليمن، حيث نصت المادة (4) من الفصل الأول منه على (الحصول على المعلومات حق من حقوق 
3. المعلومات التي يؤدي الكشف عنها الإخلال بالمنافسة المشروعة أو حقوق المؤلف والملكية الفكرية.

4. معلومات وملفات الأشخاص التعليمة، أو الطبية، أو الوظيفية، أو حساباته المصرفية أو أسراره المهنية دون موافقته، وكل ما يتعلق بسلامة وصحة المواطن

وتعريض حياته للخطر.

5. البيانات التي يتسبب الإفصاح عنها إختزاق السبكات الألكترونية المحمية ويعرض محتوياتها للمحو أو السرقة. ثاثلاً : الإستثناءات الواردة في قوانين أخرى نافذة في أقليم كوردستان بما لا يتعارض مع أحكام هذا القانون. رابعاً : يتم كثف المعلومات الواردة في البنود (1، 2، 3) من

$$
\text { الفترة (ثانياً) من هذه المادة بعد مضي (20) عشرين سنة). }
$$

وعند مطالعة الإستثناءات الواردة في القانون نجدها مذكورة على سبيل الحصر وهي خالية من المصطلحات المطاطة أو الغامضة أو التي تقبل أكثر من تفسير وهو ما يحمد عليه المشرع الكوردستاني، وإذا ذهبنا إلى أبعد من ذلك نجدها متطابقة مع المعايير

الدولية(45).

\subsection{2}

أوضح قانون حق الحصول على المعلومات محل الدراسة، كيفية تقديم الطلب للحصول على المعلومات من خلال انموذج معتمد لهذه الغاية، على أن يتضمن الطلب اسم مقدمه ومكان اقامته وعمله اضافة الى تحديد موضوع المعلومات التي يرغب في الحصول عليها بدقة ووضوح (46). وحددت الفقرة (5) من المادة (7) فترة الاجابة على طلب المعلومة وأكدت على المسؤول اجابة الطلب أو رفضه خلال (10) أيام من اليوم التالي لتاريخ تقديمه وإمكانية التمديد إلى (15) ولمرة واحدة فقط وبشروط مذكورة في نص القانون، واشترطت الفقرة (ثالثاً) من المادة (8) انه في حال رفض الطلب أن يكون القرار معللاً ومسبباً ويعتبر الامتناع عن الرد ضمن المدة المحددة قراراً بالرفض، وفي حال رفض الاجابة على طلب اعطاء المعلومة حددت الفقرة (4) من المادة (8) محكمة البداءة للنظر في قرار رفض طلب الحصول على المعلومات. يككن أن نلاحظ أن المشرع قد أخفق في إختيار المحكة المختصة للنظر في قرار رفض تزويد الشخص بالمعلومات، حيث أن قرار الرفض يعتبر قراراً إدارياً حضاً وبكل مقايس ومعايير القانون الإداري، عليه كان الأجدر بالمشرع منح صلاحية النظر في الطعون المقدمة ضد قرارات الرفض للمحكمة الإدارية دون غيرها، في حين كان المشرع موفقًا في تحديده
مقابل تقديم المعلومة وإعدادها (42)، الأمر الذي سيشكل عائقاً أمام طلبها إذا ما بالغت تلك المؤسسة في تقدير النفقات.

\section{6 حت الحصول على المعلومات في قانون أقليم كودستان - العراق المرق (11)}

لسنة 2013

حرصت التشريعات الوطنية والمواثيق الدولية على تنظيم حق الحصول على المعلومة، بإعتباره حق أساسي للانسان، ويسهم في دع حرية الرأي والتعبير، وتنمية الديمقراطية والشفافية، ولضمان إحترام حق الحصول على المعلومات في أي دولة، الأمر الذي يفرض على الدول التي أنضمت إلى تلك الإتفاقيات تشريع قانون خاص ينص ينظم هذا الحق، وقد وضعت الكثير من الدول في العالم قوانين لضمان مارسة هذا الحق، وتماثياً مع هذا التوجه أصدر برلمان أقليم كوردستان القانون المرق (11) لسنة 2013 والموسوم بقانون حق الحصول على المعلومات لأقليم كوردستان العراق. لقد وضعت منظمة المادة (19) عدداً من المعايير والضمانات القانونية الواجب توفرها في التشريع المنظم لهذا الحت، والتي تمت الإشارة إلهيا في بداية هذا البحث، سنحاول في هذا المبحث تناول هذه المعايير تباعاً ومدى إلتزام المشرع الكوردستاني بها وذلك كما يلي :

\section{6 .1 مبدائي الكشف الاقصى، ومحدودية استثناءات النشر}

أشارت المادة (4)(43) من قانون حق الحصول على المعلومات المرق (11) لسنة 2013، إلى حق كل شخص في الحصول على المعلومات، ورغز أن النص قد جاء مطلقاً إلى أنه لا يكن إعتبار أن القانون يسمح للأجانب ممارسة هذا الحت خاصة إذا أطلعنا على أهداف هذا القانون والتي نصت على (تمكين مواطني الأقليم من ممارسة حقهم في الحصول على المعلومات لدى المؤسسات العامة والخاصة وفقاً لأحكام هذا القانون)(44)، كما منح القانون الحق للمؤسسة ان تمتنع عن الكشف عن المعلومات في حالات محددة ومذكورة على سبيل الحصر وذلك في المادة (14) من القانون المذكور بقولها (أولاً : لا يجوز للمؤسسة العامة أو الخاصة رفض إعطاء المعلومات حهاية لمصلحة واردة في الفقرة (ثانيا) من هذه المادة إذا أقتضت المصلحة العامة كثفها. ثانياً : للمؤسسة العامة أو الخاصة الحق في رد طلب المعلومات في الأحوال الآتية : 1. الأسرار الخاصة بالدفاع وأمن أقليم كوردستان. ....

2. المعلومات التي تؤدي الكشف عنها إلى الثأثير على سير المفاوضات التي يجرهها الأقليم مع أية بجة أخرى........ - ل 
2. تبين لنا ان العديد من الدساتير العربية التي عالجت موضوع حق الحصول على المعلومات قد ضيقت وبشكل كير من نطاق الاشخاص الذي يحق لم طلب الاطلاع على المعلومات مثل ( الدستور المصري والمغربي ) حيث منحت هذه الدساتير هذا الحق للمواطن فقط دون الاجانب وهذا بحد ذاته يتعارض مع مبادئ المنظمة 19 الخاصة بحرية الرأي والتعبير والتي تستوجب وضع المعلومات في متناول الجميع دون تميز بين المواطن والاجنبي المقيم على اقليم الدولة.

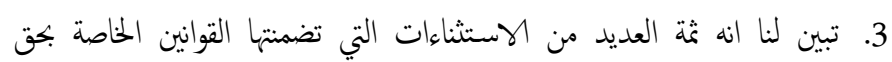
الحصول على المعلومات , حيث يتم بذريعتا الامتناع عن تقديم المعلومات عند طلهيا مثل ( الامتناع عن تقديم المعلومات بدافع الحفاظ على النظام العام او الامن القوي للدولة. . . . الخ ) وهذه الاستثناءات دون شك تؤدي المى الاضعاف من قيمة هذا الحق ودوره في تحقيق الحكم الرشيد ومحاربة الفساد في الدولة. 4. الملاحظ على اغلب القوانين الخاصة بجق الحصول على المعلومات انها لم تحدد وبشكل دقيق معنى بعض المصطلحات التي تشكل استثناءات ترد على امكانية طلب المعلومة مثل ( النظام العام , الامن القوي , المصلحة الشخصية للمواطن ) وانما اكتفت بذك هذه المصطلحات بشكل عام ومما لا شك فيه ان هذا الامر سيمكن الجهات القائمة على حفظ المعلومات من اللجوء الى المعنى الواسع لها الامر الذي يضيق من نطاق المعلومات التي يكن طلهيا او الاطلاع عليها من قبل الاشخاص. 5. كما تبين لنا ان اغلب القوانين الوطنية التي تناولت بالتنظيم حق الحصول على المعلومات لم تحدد تكلفة الحصول على المعلومات وهذا بحد ذاته يشكل نقطة سلبية تسجل ضد هذه القوانين لان عدم تحديد هذه التكلة وترك مسالة تقديرها للجهة التي تختفظ بالمعلومة قد تدف تلك الجهات المى المغالاة في تقديرها الامر الذي يحول دون طلبها من قبل الاشخاص في حالة اثقال كاهلهم مادياً بها. 6. تبين لنا ان اغلب التشريعات التي عالجت موضوع حق الحصول على المعلومات تداولها لم تعتمد الية النشر المسبق للمعلومات في حين كان من المفترض اعتمد اسلوب النشر الاتتباقيي للمعلومات من قبل هذه التشريعات على الاقل بالنسبة لعض المعلومات ذات الصلة بالرأي العام. 7. كما تبين لنا ان الدستور العراقي الدائم لسنة 2005 لم يتطرق المى حق الحصول على المعلومات، فضلاً عن عدم اصدار المشرع العراقي لتشريع خاص بهذا الحق على لى لي
المدد الخاصة بالإجابة على الطلبات، حيث جاءت هذه المدد متطابقة مع السقوف الزمنية المنطقية والمعقولة والمدرجة في معايير منظمة المادة(19).

\subsection{3 مبدأ تحديد كلةة الوصول الى المعلومات}

نصت الملادة (15) من قانون حق الحصول على المعلومات على ان ( يتحمل مقدم الطلب تكاليف الحصول على المعلومات المطلوبة) وهذا يعطي سلطة تقديرية لتحديد التكلة المادية للحصول على المعلومات، بما أن المشرع قد منح الصلاحية للجهة المطلوب منها المعلومات تحديد هذه الكلفة، كان من الأجدر به إضافة فقرة أخرى إلى هذه المادة وهي (يجب أن لا تحول هذه الكلفة دون أن يتقدم الأشخاص بطلب الحصول على المعلومات) حتى لا تكون سلطة الإدارة مطلقة في تقدير هذه الكلفة.

\subsection{4 مبدأ الشفافية في نشر المعلومات}

لا يقتصر تنظيم حق الحصول على المعلومات على حق الأفراد في الحصول على المعلومات فقط بل يمند إلى أبعد من ذلك، حيث يفتزض على المؤسسات- العامة والخاصة - أن تقوم بنشر المعلومات الخاصة بها في موقعها على شبكة الأنتريت، الأمر الذي يتطلب إعتاد وسائل متقدمة ومتطورة في حفظ وأرشفة الوثائق والمعلومات الموجودة بحوزة هذه المؤسسات وتدريب موظفيها تدريباً متوافقًا مع الآليات الممتمدة لحفظ المعلومات والوثائق، هذ من جهة ومن بجة أخرى، يجب إستخدام وسائل الإعلام الإستخدام الأمثل لتعزيز شفافية العمل في المؤسسات - العامة والخاصة. وقد أفلح المشرع الكوردستاني عندما فرض على كل مؤسسة عامة ضرورة إصدار دليل سنوي يتضمن معلومات كاملة عن أعالها مثل هيكلها الإداري ووسائل الإتصال بها وميزانيتها ومشاريعها والشكاوى المقدمة إلها والإجراءات المتخذة بخصوص هذه الشكاوى وغيرها الكثير من المعلومات (47).

خاتمة

في ختام هذا البحث توصلنا الى بموعة من الإستنتاجات والتوصيات ندربها على

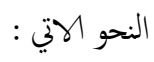

3. 1 الإستنتاجات

1. تبين لنا ان المقصود بجق الحصول على المعلومات هو تمكين الاشخاص من مصادر المعلومات والاحصاءات والاستفسار عنها والاطلاع على كافة الوثائق من مؤسسات الدولة الرسمية وغير الرسمية التي تقدم خدمة عامة دون اي عائق. 
5. ندعو المشرع الكوردستاني إلى ضرورة تحديد كلفة الحصول على المعلومات بموجب تشريع خاص، وعدم ترك هذه المسألة للجهة القائمة على حفظ المعلومات، لان هذه الاخيرة قد تبالغ في نققات تقديم هذه المعلومات، الامر الذيحول دون طلبها من

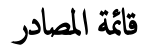

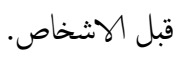

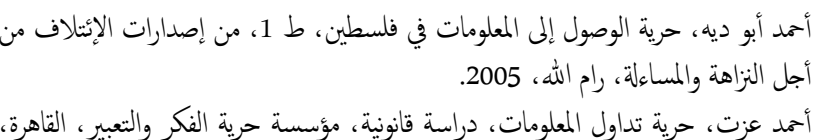

2011

3. توبي مندل، حرية تداول المعلومات، مطبوعات اليونيسكو، 2003.

4.

5.

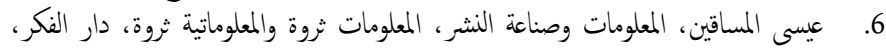

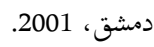

ليلى عبدالجيد، تشريعات الإعلام في مصر وأخلاقياته، ط 3، دار النضة العربية، القاهرة،

2008

8. نو قانون حرية تداول المعلومات في مصر، من إصدارات مرصد الموازنة العامة وحقوق

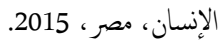

الزيه المهدي، المدخل لدراسة القانون، الجزء الثاني، نظرية الحق، دار النزة العربية، القاهرة،

.1998

10. ياسر أحمد كامل الطريفي، دروس في المدخل لدراسة القانون، الجزء الثاني، نظرية الحق، د.

ن، 1996.

الرسائل والأطاريح

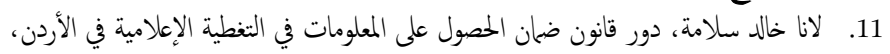

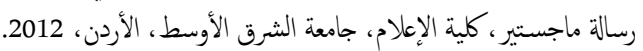

\section{الدسائير والقوانين الوطنية}

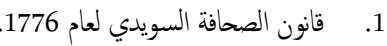

2.

3. الميثاق الأمريكي لحقوق الإنسان لعام 1969.

4.

5.

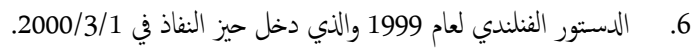

7.

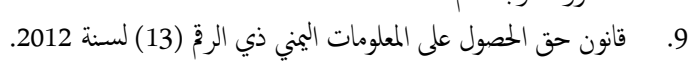

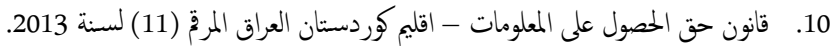

11. الدستور المصري لعام 2014.

12.

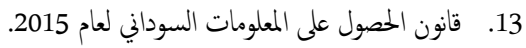

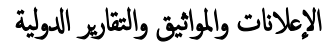

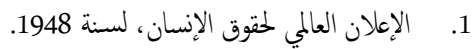

2.

3.

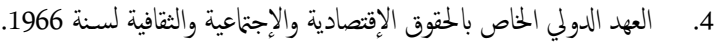

غرار ما هو موجود في العديد من الدول العربية، وهذا بحد ذاته يجعل من التشريع العراقي بعيداً عن التشريعات الديمقراطية في هذا الصدد قدر تعلق الامر بهذا الحق. 8. تبين لنا ان المشرع في كوردستان - العراق كان موفقاً المى حد كبير في اصدار قانون خاص بحق الحصول على المعلومات حيث جاء هذا القانون مراعياً وبنسبة كبيرة المبادئ التي اقرتها منظمة المادة 19 الخاصة بحرية تداول المعلومات , وهذا بحد ذاته يشكل نقطة ايجابية تسجل لصالحه.

3. - 2 2 التوصيات

1. ندعو المشرع الدولي الى اعتاد اتفاقية دولية خاصة بحق الحصول على المعلومات وتداولها على ان تتضمن المعايير التي حددتها منظمة المادة 19 الخاصة بحرية الرأي والنعبير , حيث ابرام هكذا نوع من الاتفاقيات سيحقق العديد من الفوائد اهمها : أ. القضاء على التشتت الذي يعتري معالجة هذا الحق دولياً بسبب تناوله في العديد من المواثيق الدولية الامر الذي يثقل كاهل الدول من ناحية ويضعف من امكانية

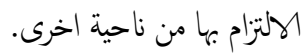

ب. ستلعب هكذا اتفاقية في حال ابرامها دوراً حماً في تحقيق الشفافية والحكم الرشيد

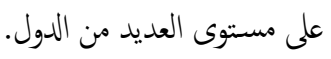
2. ـدعو المشرع العراقي الى ضرورة اعتماد قانون خاص بحق الحصول على المعلومات وتداولها لان اعتمد مثل هذا القانون سيارس دوراً حماً في تحقيق الشفافية ومحاربة

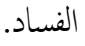
3. نتّزح على المشرع الكوردستاني إعادة دراسة قانون حق الحصول على المعلومات المرة (11) لسنة 2013 وذلك للحد من الاستثناءات التي ترد على هذا الحق , فضلاً عن تحديد المقصود بهذه الاستثناءات وعدم اطلاق المصطلحات التي تشكل استثناءات على عموها مثل ( النظام العام وغيرها من المصطلحات ) لان الابقاء على هذه المصطلحات بصينتها العامة سيعطي للجهات القائمة عليها سلطة في تفسيرها بشكل موسع مما يفقد هذا الحق قيمته الفعلية او الحتقية. 4. نقزح على حكومة اقليم كوردستان بإعتبارها الجهة الحائزة للكم الأعظم من المعلومات، أن تعتمد أسلوب النشر الاستباقي للمعلومات، خاصة تلك المعلومات التي تتعلق بالرأي العام، لان إعتماد هذا الاسلوب سيخفق بشكل كير من النعقيدات التي ترافق إجراءات الحصول على المعلومات في حال طلها من قبل الاشخاص. 
13. للمزيد ينظر: 2016/05/23/udhr-article19 تاريخ الزيارة 15-2018.

14. الإتفاقية الأوربية لماية حقوق الإنسان وحرياته هي عبارة عن معاهدة دولية تهدف إلى حاية

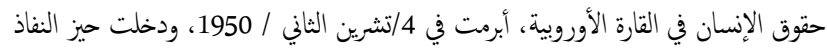
في 3 اديسمبر / 1953. 15. الفقرة (1) من المادة (10) من الإتفاقية الأوربية لحقوق الإنسان لعام 1950.

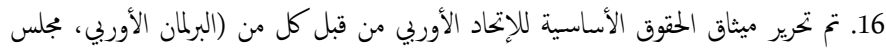

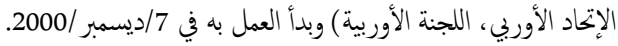

17. ينظر المادة (11) من ميثاق الحقوق الأساسية الأوربي لعام 2000.

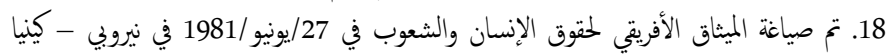

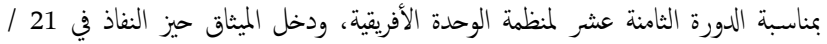
أكتوبر / 1986 بعد أن صادقت عليه (25) دولة من الدول الأفريقية. 19. ينظر المادة (9) من الميثاق الأفريقي لعام 1981 المادق عاليه

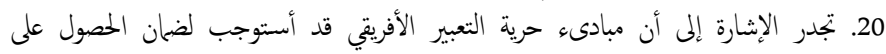
المعلومات مراعاة المبادىء التالية: يحق للجميع الحصول على المعلومات التي تحتفظ بها بجات عامة.

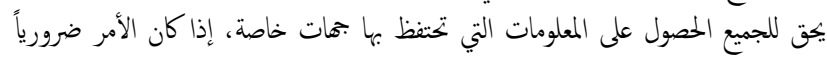
لملمارسة أي حق أو حايته.

3. إن رفض الكشف عن المعلومات يخضع للألتماس إلى أية بحة مستقلة أو إلى المحاكم.

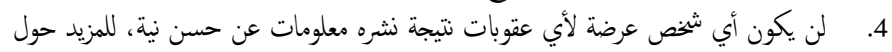

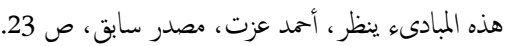

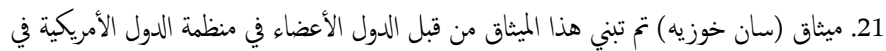

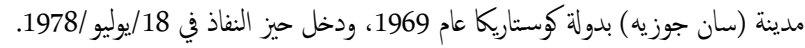

22. ينظر المادة (13) الفقرات (1-23) من الميثاق الأمريكي لحقوق الإنسان لعام 1969.

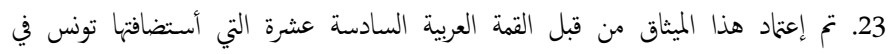
2004/23 / 200

24. لقد شهد تعريف الحق خلافاً واسع النطاق بين فقهاء وشراح القانون الأمر الذي أدى إلى إلى

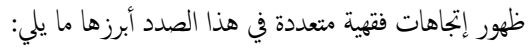

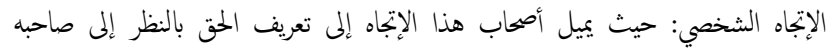

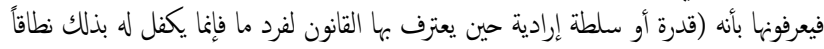

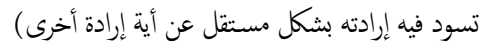

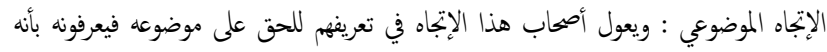

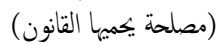
نظرية الجمع بين الإرادة والمصلحة: يذهب أصحاب هذا الإتجاه في تعريفهم للحق إلى الجمع بين

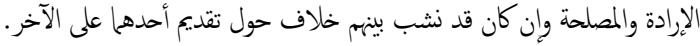

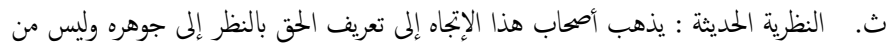

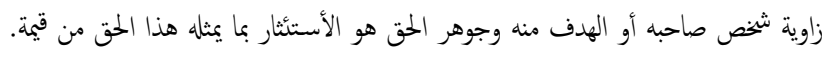

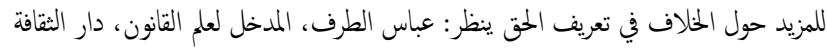

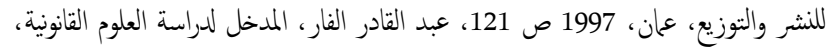

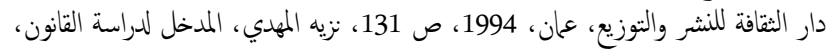

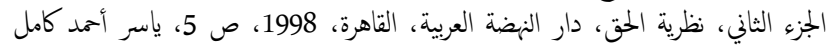

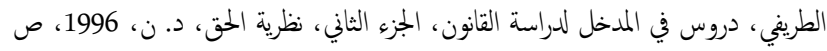

25. للمزيد حول تعريف المعلومات ينظر ، عيسى المساقين، المعلومات وصناعة النشر، المعلومات

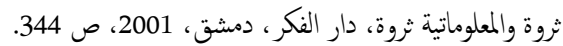

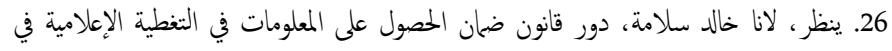

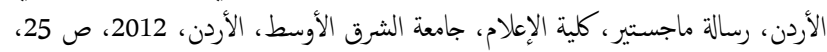

5.

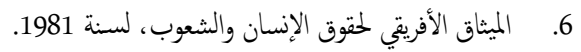
7.

8.

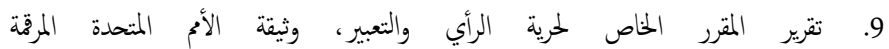
(1998\Dec \40\28\1998\Eicn. 4)

المصادر الألكترونية

1. حرية المعلومات - مسح قانوني مقارن، منشورات منظمة اليونسكو، متوافر على الرابط التالي :

http : //www. unesco. org/new/en/communication-andinformation/freedom-of-expression/freedom-of-information

2. https : //emadbk. wordpress. com/2016/05/23/udhr-article19/

1. تم إعتماد هذا الإعلان من قبل المجعية العامة للأمم المتحدة بموجب قرارها المرقٍ (217) الف (د -

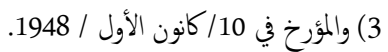

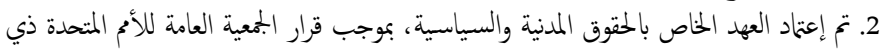

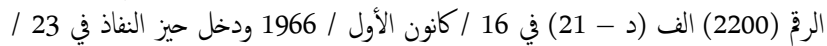

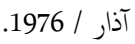

3. تجدر الإثشارة إلى أن ممارسة الحقوق المنصوص علها في الفقرة (2) من المادة (19) من العهد

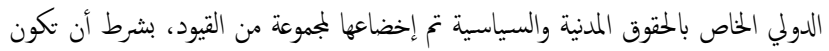
محددة بنص القانون وأن تكون ضرورية لكي تحقق ( 1. إحترام حقوق الآخرين وسمعتهم 2.

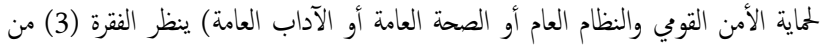
المادة (19) من العهد الخاص بالحقوق المدنية والسياسية.

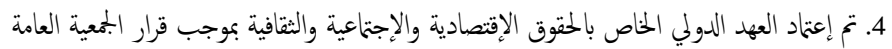

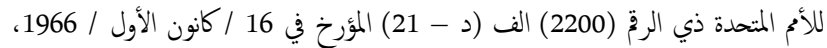
ودخل حيز النفاذ عام3 / كانون الثاني / 1976. 5. أحمد عزت، حرية تداول المعلومات، دراسة قانونية، مؤسسة حرية الفكر والتعبير، القاهرة،

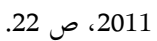

6. تم إنشاء ولاية المقرر الخاص المعني بتعزيز وحاية الحق في حرية الرأي والتعبير بموجب القرار ذي الماري

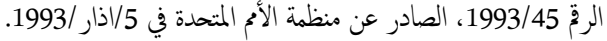

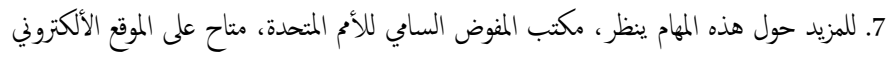

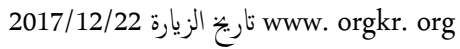

8. تقرير المقرر الخاص لخرية الرأي والنعبير، وثيقة الأمر المتحدة المرقة (1998\Dec\40\28\1998\Eicn. 4)

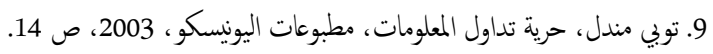

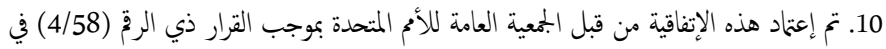

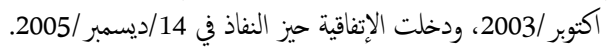

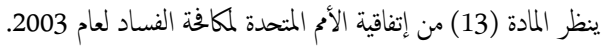

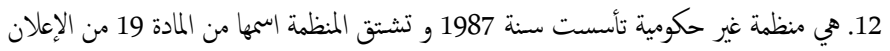

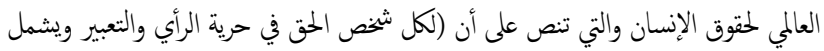

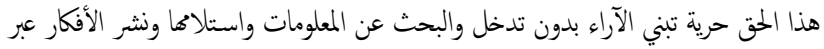

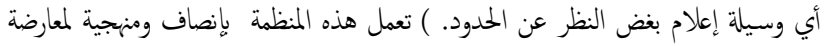

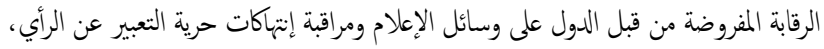

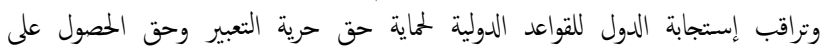

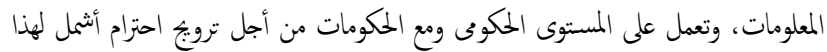

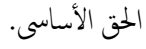
للمزيد حول هذه المنظمة ينظر موقعها على شبكة الأنتريت (تاريخ الزيارة 11-19-2017): https://www. article19. org 
47. ينظر المادة (6) من قانون حق الحصول على المعلومات لأقليم كوردستان - العراق المرق (11)

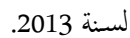

ليلى عبدالجيد، تشريعات الإعلام في مصر وأخلاقياته، ط 3، دار النضخة العربية، القاهرة،

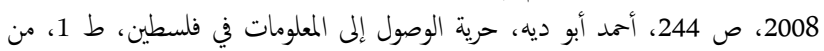

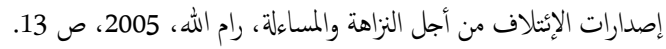
27. ينظر الفقرة (1 / د) من المادة (20) من الدستور الإسباني لعام 1978 وتعديلاته لغاية عام 2011

$$
\text { 28. ينظر الفقرة (2) من المادة (20) من الدستور الإسباني. }
$$

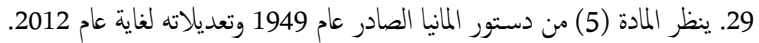

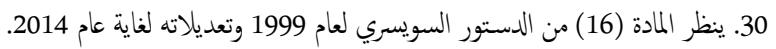

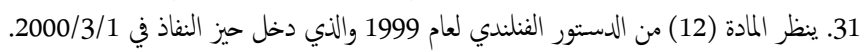

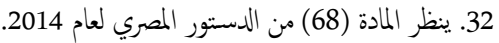

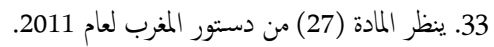

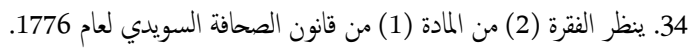
35. 35 ينظر المادة (3) من القانون أعلاه

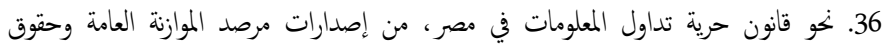

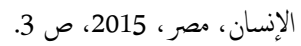

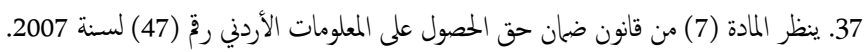

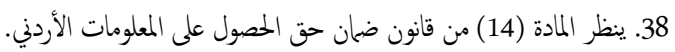

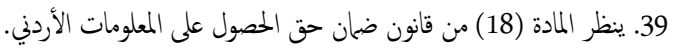

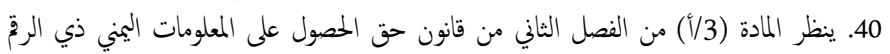

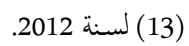

41. ينظر المادة (7) من قانون حق الحصول على المعلومات الفلسطيني لسنة 2015.

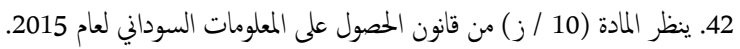

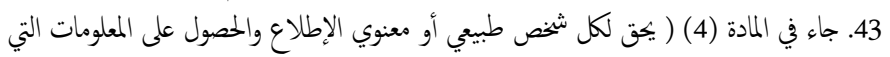

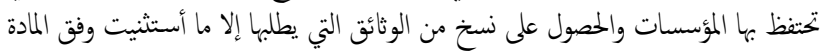
(14) من هذا القانون). 44. الفترة (1) من المادة (2) من قانون حق الحصول على المعلومات - اقليم كوردستان العراق المرج (11) لسنة 2013.

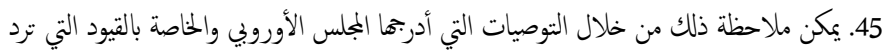

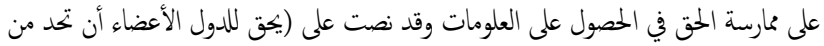

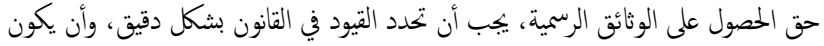

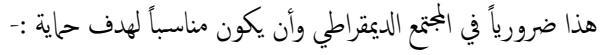
أ. أ. الأمن القوي والعلاقات الدفاعية الدولية.

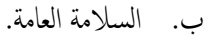
ت. ت. التحقيق في النشاطات الإجرامية وملاحقتها. ث. ت الخصوصية وأية مصالح مشروعة خاصة.

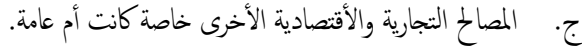

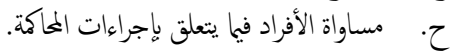

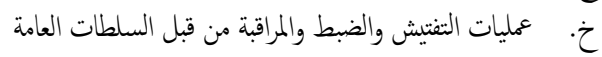
د. سياسات الدولة الإقتصادية والنقدية الخاصة بسعر الصرف. ذ. س سرية النداول ضمن أو بين السلاطات العامة أثناء الإستعدادات الداخلية لمسألة ما.

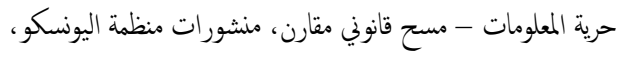
http://www. unesco. org/new/en/communication-andinformation/freedom-of-expression/freedom-of-information تاريخ الزيارة 12-12-18018، ص 53. 46. المادة (7) من قانون حق الحصول على المعلومات لأقليم كوردستان - العراق المرخ (11) لسنة 